\title{
Exploring Personal Factors That Might Influence the Vulnerability of Construction Employees to Occupational Psychological Disorders
}

\author{
Genevieve Ataa Fordjour ${ }^{1 *}$, Albert P. C. Chan'1, Peter Amoah ${ }^{2}$ \\ ${ }^{1}$ Department of Building and Real Estate, The Hong Kong Polytechnic University, Hong Kong, China \\ ${ }^{2}$ Department of Building Technology, Kwame Nkrumah University of Science and Technology, Kumasi, Ashanti, Ghana \\ Email: *genevievefordjour@gmail.com, albert.chan@polyu.edu.hk, peteramoah@knust.edu.gh
}

How to cite this paper: Fordjour, G.A., Chan, A.P.C. and Amoah, P. (2019) Exploring Personal Factors That Might Influence the Vulnerability of Construction Employees to Occupational Psychological Disorders. Health, 11, 546-566.

https://doi.org/10.4236/health.2019.115047

Received: April 23, 2019

Accepted: May 26, 2019

Published: May 29, 2019

Copyright () 2019 by author(s) and Scientific Research Publishing Inc. This work is licensed under the Creative Commons Attribution International License (CC BY 4.0).

http://creativecommons.org/licenses/by/4.0/

\begin{abstract}
Personal factors could act as intervening variables between the causes and effects of psychological health conditions of employees. This study focused on six personal intervening factors that were associated with the risks of occupational psychological disorders namely: low self-esteem, negative personality trait, unproductive core beliefs, poor self-concept evaluation on performance, poor relationship with others and poor time management skills. An investigation on the level of severity of these personal intervening factors was conducted involving 150 construction professionals and 150 construction trade workers, who were purposively selected in Ghana. The personal factors that were found to be prevalent among the construction employees were low self-esteem and poor time management skills. Correlation analysis and regression analysis were used to determine the relationships between the personal intervening factors and demographic factors such as the age, educational levels and marital status of the research participants. The results of the study indicated that the age and marital status of the respondents had no significant relationship with any of the personal intervening factors. Personal factors such as personality trait and relationship with others also had no relation with any of the demographic factors analyzed. The educational level of the respondents, however, had a significant relationship with the factors of self-esteem, productive core beliefs, self-evaluation on performance and time management skills. An independent two-sample T-test was used to compare the means of the factors with significant relations. This study revealed that construction employees who were highly educated had better self-esteem and time management skills than those who were less educated. The findings from this study broaden the view of moderators on influential sources of psychological health conditions of employees.
\end{abstract}




\section{Keywords}

Occupational Psychology, Psychological Disorders, Personal Factors, Construction Employees, Ghanaian Construction

\section{Introduction}

Psychology in the workplace stretches beyond the boundaries of the physical settings of the workplace [1]. Previous researchers revealed that psychological health conditions of employees such as stress, depression, anxiety, and frustration were influenced not only by exogenous events but also by factors that emanated from the workplace [2]. Factors that cannot be found in the work setting also influenced employees' behaviors and psychological health conditions [1]. These factors may include cultural, environmental influences, personality, family background, relationship responsibilities, employment-related requirements and non-working events [1] [3]. Other endogenous factors such as employees' perception or core beliefs also arouse the circumstances which led to an individual's experiences of psychological health conditions [2] [3]. It was revealed in a study by Mäkikanges et al. [4] that, there was a positive relationship between personal factors of employees such as self-esteem and their occupational psychological health, specifically burnout and work engagement. Earlier research by Leung et al. [5] also established some link between individual characteristics such as Type A and Type B behaviors of some construction personnel and their occupational psychological health such as stress, with relative effect on their work performance.

Personal factors of employees such as self-esteem, productive core beliefs, time management skills, and good relationship with other employees could to some extent mitigate the causes and mediate the effects of psychological disorders [1] [2]. The concept of personal factors fit in occupational psychology and researchers have suggested that for the least circumstances of psychological disorders, there is a need for a balance between personal characteristics and organizational factors [6]. Personal factors are, however, remarkable intervening variables in the occupational psychological equation; this is because what may be overtaxing to one person may be exhilarating to another [7]. Typical construction work, for instance, involves several people from different backgrounds with diverse personality, coming together to form a working team. Personal strengths and vulnerabilities of the construction employees are significant to their experiences of psychological health conditions [6].

There is little research with attention paid to the influence of personal factors on the psychological health of employees in the construction industry. This research seeks to explore among construction employees, the personal factors that could make them vulnerable to the potential sources and effects of occupational psychological disorders. In addition, this study sorts to investigate the relation- 
ship between personal intervening factors and some demographic factors.

\section{Background of Research}

Potential causes of psychological health conditions of construction employees which emanate from their construction work could include abusive and over demanding supervisors, tight deadline pressures, limited time for relaxation and poor working conditions [2] [6] [8]. The psychological risk factors which could emanate from the construction workplace have been categorized into high task demands, high role demands, poor organizational factors and poor working relationships [8]. These work factors could lead to the triggering of psychophysical response or reaction by the construction employees and hence could affect the employees' psychological well-being and health [1]. The effects of these construction work-related psychological health risk factors have both individual and organizational consequences [5].

The individual consequences of psychological disorders on construction employees could be manifested in various forms of behavioral, physiological and emotional symptoms [1] [3]. For instance, employees in the construction industry who are extremely competitive and task-burdened would be likely to be subjected to occupational psychological disorders of workaholism and burnout, with associated symptoms such as emotional distress and other physical health problems [7]. Construction employees specifically construction professionals or project team members (such as Architects, Quantity Surveyors, and Engineers) and construction trade workers (such as carpenters, masons and plumbers) are considered generally as vital resources for the success of every construction project [5] [8]. The psychological health conditions of construction employees could lead to both direct and indirect cost consequences on the construction industry such as low productivity, poor job performance and increase in medical costs [6] [7].

Positive personal factors could serve as modifiers in terms of psychological appraisal, modulators of individual responses to psychological risk exposures and moderators of the consequences of one's reactions to the effects of psychological disorders [3] [6]. Personal factors are among the antecedents of psychological issues such as stress, which is typical among employees in the construction industry [8]. Coping with the construction work-related factors that are triggers of employees' psychological health conditions, would therefore necessitate positive individual personal factors of the construction employees such as: good attitude, positive perception and lifestyle, as their efforts to deal with or manage the triggers and/or effects of the psychological disorders [2] [8]. Individual responses to psychological risk exposures may vary greatly with immediate or long-term consequences of their reactions [1]. The variance in responses to psychological triggers is often influenced by individual personal factors [6]. Each construction personnel has a distinctive personal characteristic, which indicates their level of resistance to psychological disorders [5]. The individual 
employees' characteristics join to further murky the nature of their psychological health condition.

Differences in personal factors put individual employees at a lesser or greater risk of experiencing occupational psychological disorders [9]. The personal factors of an employee may, therefore, in part affect the frequency of exposure to conditions that are unfavorable to the psychological health condition of that individual, but more importantly, may modify the severity of experience associated with such conditions [10] [11]. Individual differences can be seen in the level of a person's desire to succeed and achieve results, a person's ability to cope with his or her need for urgency, how much one feels able to influence and control events, the extent to which one plans and manages his or her time to deal with problems [9] [12]. Researchers have suggested that a person's degree of vulnerability, extroversion, compulsiveness, and belief in his or her abilities to respond to difficult or novel situations and possible stressors might influence his or her level of psychological health condition [13].

A six-dimensional personal factors model associated with psychological health conditions has been advocated by previous researchers to include: self-acceptance, environmental mastery, autonomy, positive relations with others, personal growth and purpose in life [14] [15]. In addition, Quick et al. [6] revealed personal factors, such as demographic characteristics, internal capabilities, personality traits, attitudes and behaviors as factors influencing employees' psychological health conditions. Bono and Judge [16] also indicated in their study that, core personal factors associated with individuals' psychological health conditions were self-esteem, neuroticism, locus of control and generalized self-efficacy. Notwithstanding, high levels of a psychological risk factor can overwhelm relatively high levels of individual capacity resulting in negative consequences of psychological disorders [6]. Personal factors can also be influenced by several other factors including the events that took place before the person attained a full-time job [1]. Personal factors could, therefore, predispose employees to either less or greater risk of psychological disorders [9].

\section{Personal Factors Associated with Employees' Psychological Health Condition}

A research study by Martinko et al. [17] indicated that differences in peoples' characteristics influenced their reactions to and perceptions of occupational psychological issues. A study conducted by Mäkikangas et al. [4] also revealed that personal-related factors such as self-esteem, locus of control and neuroticism, had a relationship with employees' occupational psychological disorders, such as burnout and workaholism. In addition, O'Donoghue et al. [2] advocated that employees who had positive core self-esteem, positive beliefs, low pessimism, low neuroticism, strong personal worth and sense of control over their own life and events, were less likely to experience occupational psychological disorders. This current research study seeks to add to the study of personal psychology in the workplace by exploring the factors of self-esteem, personality trait, core 
beliefs, self-evaluation on performance, relationship with others and time management skills among construction employees. The demographic factors of the respondents such as their age, educational level, and marital status are considered as possible predictive variables of the personal intervening factors associated with psychological health.

\section{Self-Esteem}

Self-esteem is characterized by ones' self-acceptance and environmental mastery [2]. That is, a person with self-esteem has self-acceptance and is exhibited by one's positive evaluation of his or her past [6]. Environmental mastery is also depicted by one's capacity to effectively manage his or her life and events [14]. Tims et al. [18] in their study established a relationship between self-esteem and psychological well-being indicators such as work engagement. The researchers stated that to improve work engagement, leaders of an organization should enhance and optimize the employee's personal resources, specifically self-esteem [18]. Burnout, one of the occupational psychological ill-being indicators, has also been seen to be moderately influenced by a person's locus of control, this depicts positive self-esteem [19].

Previous research works advocated that there is a need for people to see themselves as unique and differing in various aspects from others, as no two persons are the same [20]. Social acceptance is one of the basic needs of all humans, as this could influence a person's psychological well-being. It is worth noting that, individual's attitude, likings, disliking, perceptions, opinions, and mindsets, could be different from person to person, even though they might be exposed to similar situations [21]. These differences should not affect how people regard themselves as good or bad.

\section{Personality Traits}

The qualities and characteristics of a person can influence how they cope with their life experiences, with effects on their psychological health conditions [2]. Employees' individual behaviors form their personality traits, which influences their psychological health. The individual behaviors can be grouped under Type A and Type B behaviors [12]. Evidence shows that Type A persons are more likely to experience psychological disorders than Type B individuals [22]. People with Type A behaviors are characterized by impulsiveness, aggressiveness, hostility, time-driven attitudes and difficulty relaxing. The Type B personality on the other side, is more placid and easy going [8]. Earlier research conducted by Anderzen and Arnetz, however, indicated that Type A behavior had limited impact on the psychological health conditions of employees [23]. This statement was contradicted by Lee and Sukoco, who reported that personal factors such as Type A behaviors were significant to employee's psychological health and well-being [24].

A person's level of neuroticism and or self-efficacy has also been revealed to be significant predictors that predisposes employees to psychological health conditions [6]. Self-efficacy is the belief in one's ability to handle novel and challenging situations [2]. Neuroticism, on the other hand, is a person's degree 
of vulnerability or sensitivity to criticism [16]. Persons with high levels of self-efficacy are hypothesized to be more effective in dealing with difficulties and are more persistence in facing challenges [25]. Individuals who are highly neurotic, on the other hand, often interpret life situations and encounters as damaging or threatening [26].

According to Abbot, et al. personality factors such as extraversion, openness, neuroticism are the significant variable behaviors, accounting for an individual's psychological well-being or ill-being conditions [27]. Personality cognitive traits fall within the boundary of the theory of conservation of resources (COR) and have relevance in workplace issues [28] [29]. These personality cognitive traits include optimism, autonomy, efficacy, hope, and resilience [29]. Optimism is a personality trait, which depicts persons who have a positive outlook on their life events and situations [26]. An optimistic individual considers the sources of good or positive events as universal and permanent, while a pessimistic individual attribute the source as temporary and situation-specific [30]. Autonomy refers to having the ability to do what one chooses, think and or act in certain ways and ones' ability to resist pressures from external sources [14]. Resilience can be found in individuals, who perceive their life to be meaningful [2]. People who are resilient usually can 'bounce back' from life adversities and have high capacities for adaptation and improvisation [30]. These personality traits in effect influence the employees' level of job satisfaction and work performance [16].

\section{Productive Core Beliefs}

The core beliefs a person hold dearly could influence their psychological ill-being and well-being conditions [2]. Every employee has different causational factors and breaking points when it comes to life stressors [31]. One's conviction about his or her abilities to mobilize cognitive resources or course of action needed to successfully execute a given task, reflects a person's core beliefs [6]. Thus, personal beliefs could lead to psychological ill-being conditions such as burnout [32]. A person's belief affects their ability to deal psychologically with problems and cope with environmental conditions [6]. This personal belief also has effects on a person's level of success in all aspects of life [14].

\section{Relationship with Others}

Interpersonal relationship with people especially supervisors and co-workers at the workplace could be a significant predictor of the psychological well-being of the employee [2]. Poor relationship with people at the workplace is usually characterized by discrimination, aggression, hostility, offensive behaviors, and violence at the workplace [1] [7]. An employee who has a poor relationship with others could, therefore, be vulnerable to psychological disorders such as helplessness, low self-worth, fear, paranoia, anxiety, depression, insecurity, and even narcissism [3] [6].

\section{Self-Concept Evaluation on Performance}

It is a fundamental requirement to determine the core-self evaluations that individuals regard themselves, as these subconsciously influence a person's behaviors, perceptions and psychological health [16]. Persons with high good self- 
concept evaluation are more resilient to face any challenges been thrown at them [33]. That is, the perceptions employees have about themselves can shape their psychological well-being [34]. Positive appraisal of all aspects of one's self and job influences their motivational, cognitive, behavioral, affective and psychosomatic dimensions, these enhance their occupational psychological well-being and health [14].

A study by Van Beek et al. [35] advocated that employees who perceived themselves as not performing well in their jobs, could be experiencing psychological ill-being symptoms such as workaholism, burnout, anxiety, and depression. It was also confirmed in a study by Aryee et al. [36] that, the performance-related outcomes of employees, could affect their psychological health. Earlier research findings by Spence and Robbins revealed that people drove themselves hard to achieve the personal goals they set for themselves such as: acquiring status, admiration from peers and approval from people such as work superiors [37]. The researchers stated however that, if people demonstrate low self-concept evaluation of their perceived performance on these life achievements, this could lead to them experiencing psychological ill-being conditions. Individuals with high positive self-concept evaluation of their mental functionality and creativity, have psychological well-being indicators such as job satisfaction and work engagement [38].

\section{Time Management Skills}

The skill adopted by an employee to self-manage his or her time is a major area of concern for an occupational psychologist, as the effect of the imbalance of work and family life could be tremendous on a person's life [1]. Poor life and work balance due to poor time management can lead to psychological ill-being conditions such as stress, and anxiety [6]. Effective time management skills can on the other hand help to reduce stress and other psychological ill-being conditions significantly. Time management, therefore, affects a person's work and life balance.

\section{Demographic Factors}

Many researchers have conducted studies to investigate the relationship between demographic factors (such as age, gender, marital status, education level, and working experience) and the risks of occupational psychological disorders (such as job burnout) [39]. Previous studies by Chaoping and Kan [40]; Erickson and Grove [41] and Johnson et al. [42] revealed that persons younger than 40 years of age were more likely to suffer from the risks of occupational psychological disorders than their older counterparts. However, similar studies conducted by Cheng et al. [43] and Ahola et al. [44] advocated that there was no correlation between age and psychological risk factors. Other researchers like Brewer and Shapard [45] also revealed that there was a small negative correlation in the relationships adding that persons are able to develop psychological coping skills as they age.

The education level of employees could impact their technical knowledge and management capabilities [39]. Some previous researchers like Du et al. [46] and 
Rashkovits and Livne [47] have argued that highly educated individuals are more rational when facing occupational psychological conditions. That is the higher one's educational level, the better one's ability to master effective ways of coping with the risks of psychological conditions to reduce its likelihood [46] [47]. Also, Mohammadpoorasl et al. [48] and Maslach et al. [49]revealed that there was a positive relationship between one's personal achievements such as marital status and the risk of psychological disorders. Thus, the expectations and responsibilities of these persons will be more difficult to meet, thereby increasing the likelihood of psychological disorders [48] [49]. This study sorts to investigate the relationship between the demographic factors of age, educational level and marital status with personal intervening psychological risk factors.

\section{Research Methods}

To explore the personal factors associated with occupational psychological health conditions among construction employees, this study adopted the methods of survey questionnaires. A target of 300 participants comprising of 150 construction professionals and 150 construction trade workers were set for this study. Large sample size of 100 and above are common with studies conducted in the construction industry [7] [50]. The research participants were selected from 32 construction companies registered under either one of the four construction works classifications in Ghana, namely: D1K1, D2K2, D3K3, and D4K4 construction industries, in the descending order according to the size of the construction company. That is the large-scale construction firms belong to $\mathrm{D} 1 \mathrm{~K} 1$, and the small-scale construction firms belong to D4K4 works classification.

A non-probability sampling technique, specifically the purposive sampling method was adopted in selecting the research participants, based on the undefined nature of their population. The participants in the study were selected on the basis that 1) they have work experience in the Ghanaian construction industry and 2) they belong to either a construction professionals' group or a construction working trade. The construction professionals group comprised of architects, engineers, quantity surveyors, contractors, supervisors, construction managers, and project managers. The construction trade working group also include carpenters, masons, plumbers, steel benders and the likes. Most of the research participants were first identified from on-going construction projects in Ghana, while others were referred by their colleague workers. Structured questionnaires were distributed face to face to the construction employees in Ghana until the target of 300 respondents was achieved.

\subsection{Ethical Considerations}

Research ethics were required to be adhered to for every research work carried out, and this study was not an exemption. Some ethical considerations for this study included allowing respondents to voluntarily participate in the study based 
on their free will, without using any form of coercion or force. The consent of each respondent was also sought to include their responses in this study. The prospective research participants were assured that the results of this study would not place any of them at the risk of criminal or civil liability nor damage their financial standing, employability or reputation. The personal information of the participants was therefore treated with confidentiality.

\subsection{Research Materials}

The six personal factors that this study focused on to determine the vulnerability of construction employees to occupational psychological disorders, were adopted from comprehensive reviews of previous studies such as O'Donoghue, et al. [2]; Quick, et al. [6] and Xanthopoulou, et al. [31]. A research questionnaire comprising of 18 closed-ended research statements were developed to suit the six measures adopted by this study. The research participants were requested to rate the level of severity or likelihood of the research statements to their personal characteristics, using a Likert scale ranging from 1 to 5 . For instance, a research statement such as "I am not satisfied with the relationship between myself and my colleagues" was rated using the following likelihood qualifications; "Very likely" rated as 5 points, "Likely" rated as 4 points, "Neutral" rated as 3 points, "Unlikely" rated as 2 points and "Very unlikely" rated as 1 point.

The demographic characteristics of the research participants specifically their age, educational level and marital status provided were used as bases for comparing groups. Using the Likert scale and likelihood qualifications, higher mean scores obtained by a group depict the participants are more vulnerable to the risks of occupational psychological disorders than the other group compared with it. The questionnaire was written solely in English as all the research participants had some level of education and could understand English.

A pilot study was conducted with 15 construction employees with more than 10 years of working experience, to test the appropriateness of the questionnaires by reviewing it. This initial exercise resulted in a modified final questionnaire with appropriate content validity that suits the target research participants.

\subsection{Hypothesis Testing Approach}

The Test statistics for this study was stated, and this was used as the basis for deciding whether the null hypothesis should be rejected or not. The value of the test statistics was 0.05 .

The null hypothesis, $\left(\mathrm{H}_{0}\right)$, assumed there is no statistically significant correlation between the personal intervening factors and the demographic variables.

The alternative hypothesis, $\left(\mathrm{H}_{1}\right)$, assumed there was a statistically significant correlation between the personal intervening factors and the demographic variables.

If the p-value $\leq 0.05$, this indicates that correlation is statistically significant, and hence the null hypothesis will be rejected, and the alternative hypothesis considered. 
If the $\mathrm{p}$-value $\geq 0.05$, this indicates that the correlation is not statistically significant, and hence the null hypothesis will not be rejected.

\section{Data Analysis}

The data obtained were subjected to quantitative analysis using the Statistical Package for Social Scientists (SPSS) version 19. Both descriptive and inferential statistics were employed for the data analysis. The demographic factors specifically age, educational level and marital status of the respondents were presented in percentage distribution. To determine whether the data obtained from the two construction working groups were normally distributed, Blom's fractional rank estimation method was employed. In order to reduce the data and ensure similar characteristics for each construct, exploratory factor analysis was done employing principal component analysis method. First, the Kaiser-Meyer-Olkin (KMO) measure of sampling was utilized to determine whether the data were suitable for factor analysis. Bartlett's test of sphericity was also employed to determine the multivariate normality of the variables measured.

To reduce the 18 items, only items with factor loadings greater than 0.7 were accepted as the principal variable under a construct. Cronbach alpha values were used to determine whether the variables grouped under each of the six constructs were internally consistent and reliable. Reliability or inter-item consistency is considered unacceptable unless the Cronbach alpha value of the construct is 0.7 or above [50]. To increase the reliability of a construct, the Cronbach alpha values of each item if deleted from the construct were known and variables with lower alpha values of less than 0.70 removed.

Other descriptive statistical forms such as mean and standard deviation were used to describe the central location of the frequency distribution and to indicate how the results of the data have been spread out respectively. Measures of the relationship between the Personal intervening factors (X) and Demographic variables $(\mathrm{Y})$ were analysed using correlation analysis. Pearson's method was adopted for the correlation analysis. Regression analysis was done to cross check the results from the correlation analysis. Multiple linear regression analysis was adopted to predict the relationship between the independent variables of $\mathrm{X}$ and the dependent variable of $\mathrm{Y}$. The inferential statistical form of independent two-sample T-test analysis was used to compare the mean scores obtained from the two construction working groups. The higher the mean score, the higher the personal factor is prevalent among that group as compared to the other group.

\section{Results and Discussion}

This section discusses the results and compares the study's findings with that of some earlier research works. The background information of the research participants from the two construction working groups have been presented in percentage distribution and shown in Table 1.

The KMO and Bartlett's test results shown in Table 2 confirm that factor analysis was appropriate for the data analysis and depicted that the results of the 
Table 1. Background information of research participants.

\begin{tabular}{|c|c|c|c|}
\hline \multirow[b]{2}{*}{ Information } & \multirow[b]{2}{*}{ Categories } & \multicolumn{2}{|c|}{ Percentage (150 Participants each) } \\
\hline & & $\begin{array}{c}\text { Construction } \\
\text { Professionals } \\
\text { group }\end{array}$ & $\begin{array}{c}\text { Construction Trade } \\
\text { workers group }\end{array}$ \\
\hline \multirow[t]{4}{*}{ Age } & $25-35$ & $27 \%$ & $20 \%$ \\
\hline & $36-45$ & $40 \%$ & $40 \%$ \\
\hline & $46-55$ & $20 \%$ & $29 \%$ \\
\hline & $>55$ & $13 \%$ & $11 \%$ \\
\hline Years of & Less than 1 year & $7 \%$ & $4 \%$ \\
\hline Working & $1-5 y r s$ & $42 \%$ & $24 \%$ \\
\hline \multirow[t]{2}{*}{ Experience } & $6-10 y r s$ & $31 \%$ & $60 \%$ \\
\hline & Above 10yrs & $20 \%$ & $11 \%$ \\
\hline Level of & Ghana Certificate Exams "A" level & $2 \%$ & $4 \%$ \\
\hline \multirow{5}{*}{ Education } & Ghana Certificate Exams "O" level & $0 \%$ & $2 \%$ \\
\hline & Junior High School level & $2 \%$ & $38 \%$ \\
\hline & Secondary School level & $4 \%$ & $9 \%$ \\
\hline & Technical or Vocational level & $40 \%$ & $40 \%$ \\
\hline & Graduate level or Above & $51 \%$ & $7 \%$ \\
\hline \multirow[t]{2}{*}{ Marital Status } & Married & $80 \%$ & $71 \%$ \\
\hline & Single & $20 \%$ & $29 \%$ \\
\hline \multirow[t]{2}{*}{ Gender } & Male & $87 \%$ & $96 \%$ \\
\hline & Female & $13 \%$ & $4 \%$ \\
\hline
\end{tabular}

Table 2. KMO and Bartlett's test.

\begin{tabular}{lcc}
\hline Kaiser-Meyer-Olkin (KMO) Measure of Sampling Adequacy. & 0.707 \\
\hline \multirow{3}{*}{ Bartlett's Test of Sphericity } & Approx. Chi-Square & $4.021 \mathrm{E} 3$ \\
& $\mathrm{df}$ & 153 \\
& Sig. & 0.000 \\
\hline
\end{tabular}

data can be relied upon [51]. As KMO value was greater than 0.50 and the Chi-Square value of Bartlett's Test of Sphericity had a significant value of less than 0.05 .

Exploratory factor analysis confirmed that there were six (6) factors, which together had a variance of about $80 \%$. The factor loadings of the 18 variables obtained from principal component analysis method have been presented in Table 3. The Cronbach alpha values of each variable if deleted from the construct have also been presented in Table 3. Variables with factor loadings and alpha values less than 0.70 were deleted from the constructs, as they are considered not good [50] [51]. The 18 variables were therefore reduced to 6 principal factors under the main constructs and used for some further analysis. 
Table 3. Factor loadings and coefficient reliabilities of personal factors.

\begin{tabular}{|c|c|c|c|c|}
\hline Personal Factors & No. & Research Statement & $\begin{array}{l}\text { Factor } \\
\text { loading }\end{array}$ & $\begin{array}{c}\text { Cronbach } \\
\text { Alpha }\end{array}$ \\
\hline \multirow[t]{3}{*}{ Low self-esteem } & 1 & $\begin{array}{l}\text { I regard myself as a failure If I do not } \\
\text { accomplish the goals I set for myself. }\end{array}$ & 0.782 & $0.717^{*}$ \\
\hline & 2 & $\begin{array}{l}\text { I feel I have made progress in life because } \\
\text { of my luck not because I deserved it. }\end{array}$ & 0.504 & 0.220 \\
\hline & 3 & $\begin{array}{l}\text { I am not successful and acknowledged by } \\
\text { others after all the hard work I put into } \\
\text { my works. }\end{array}$ & 0.450 & 0.362 \\
\hline \multirow[t]{3}{*}{$\begin{array}{l}\text { Negative personality } \\
\text { traits }\end{array}$} & 4 & $\begin{array}{l}\text { I am sensitive to criticisms and become } \\
\text { discouraged to put in my best efforts to } \\
\text { work after been blamed or criticized. }\end{array}$ & 0.715 & $0.703^{*}$ \\
\hline & 5 & $\begin{array}{l}\text { I feel resentment to people especially } \\
\text { those who do not support my decisions } \\
\text { and tend to be hostile towards them. }\end{array}$ & 0.479 & 0.324 \\
\hline & 6 & $\begin{array}{l}\text { I worry a lot and tend to be pessimistic } \\
\text { about the future. }\end{array}$ & 0.508 & 0.583 \\
\hline \multirow[t]{3}{*}{$\begin{array}{l}\text { Unproductive core } \\
\text { beliefs }\end{array}$} & 7 & $\begin{array}{l}\text { I believe no matter my work input, I will } \\
\text { still be treated unfairly. }\end{array}$ & 0.655 & 0.283 \\
\hline & 8 & $\begin{array}{l}\text { I believe I have to try hard enough so life } \\
\text { will be easy and trouble-free. }\end{array}$ & 0.341 & 0.124 \\
\hline & 9 & $\begin{array}{l}\text { I believe I have to always find the perfect } \\
\text { solution to problems. }\end{array}$ & 0.718 & $0.727^{\star}$ \\
\hline $\begin{array}{l}\text { Poor self-concept } \\
\text { evaluation on }\end{array}$ & 10 & $\begin{array}{l}\text { I am not performing very well in the } \\
\text { workplace. }\end{array}$ & 0.615 & 0.584 \\
\hline \multirow[t]{2}{*}{ performance } & 11 & I make a lot of mistakes at work. & 0.471 & 0.407 \\
\hline & 12 & $\begin{array}{l}\text { I spend a lot of time to complete a simple } \\
\text { task of the day. }\end{array}$ & 0.757 & $0.707^{*}$ \\
\hline \multirow[t]{3}{*}{$\begin{array}{l}\text { Poor relationship with } \\
\text { others }\end{array}$} & 13 & $\begin{array}{l}\text { I am not satisfied with the relationship } \\
\text { between myself and my colleagues. }\end{array}$ & 0.560 & 0.176 \\
\hline & 14 & $\begin{array}{l}\text { I often feel less trust for my superiors } \\
\text { and co-workers. }\end{array}$ & 0.691 & 0.395 \\
\hline & 15 & $\begin{array}{l}\text { I often feel less respect for other } \\
\text { employees. }\end{array}$ & 0.788 & $0.743^{*}$ \\
\hline \multirow[t]{3}{*}{$\begin{array}{l}\text { Poor time management } \\
\text { skills }\end{array}$} & 16 & $\begin{array}{l}\text { I find it difficult to complete my } \\
\text { assignments on time. }\end{array}$ & 0.715 & $0.725^{*}$ \\
\hline & 17 & I am often late for work or meetings. & 0.479 & 0.950 \\
\hline & 18 & $\begin{array}{l}\text { I hardly achieve the personal goals I set } \\
\text { for myself periodically. }\end{array}$ & 0.356 & 0.416 \\
\hline
\end{tabular}

Note: Only variables with Cronbach alpha values and factor loadings greater than 0.70 were maintained and used for further analysis; these have their alpha values marked with *.

The mean and standard deviations of the six main constructs of personal intervening factors, considering all variables under each construct have been presented in Table 4. 
Table 4. Means, standard deviations and correlations between personal intervening factors and demographic variables.

\begin{tabular}{|c|c|c|c|c|c|c|c|c|c|}
\hline \multirow{2}{*}{ Ranks } & \multirow{2}{*}{ Personal Factors } & \multirow{2}{*}{$\begin{array}{c}\text { Scaled } \\
\text { Mean }\end{array}$} & \multirow{2}{*}{ Std. Dev. } & \multicolumn{3}{|c|}{ Correlation Co-efficient } & \multicolumn{3}{|c|}{ Regression (Sig. value) } \\
\hline & & & & Age & $E d u$. & Marital & Age & Edu. & Marital \\
\hline $1^{\text {st }}$ & Low self-esteem & 11.08 & 3.316 & 0.082 & $0.370^{\star *}$ & 0.066 & 0.157 & $0.000^{* * *}$ & 0.255 \\
\hline $2^{\text {nd }}$ & Poor time management skills & 11.07 & 3.179 & 0.091 & $0.276^{\star *}$ & 0.075 & 0.116 & $0.000^{\star * *}$ & 0.194 \\
\hline $3^{\text {rd }}$ & Poor relationship with others & 9.97 & 3.251 & 0.004 & 0.014 & 0.069 & 0.950 & 0.815 & 0.234 \\
\hline $4^{\text {th }}$ & Negative personality traits & 9.75 & 3.327 & 0.002 & 0.030 & 0.059 & 0.979 & 0.660 & 0.307 \\
\hline $5^{\text {th }}$ & Poor self-concept evaluation on performance & 9.53 & 2.938 & 0.017 & $0.214^{\star *}$ & 0.054 & 0.772 & $0.000^{\star * *}$ & 0.349 \\
\hline $6^{\text {th }}$ & Unproductive core beliefs & 8.96 & 2.978 & 0.023 & $0.143^{*}$ & 0.081 & 0.695 & $0.013^{\star * *}$ & 0.164 \\
\hline
\end{tabular}

Note: - Values marked with * indicate correlation is significant at 0.05 level (2-tailed); values marked with ${ }^{*}$ indicate correlation is significant at 0.01 level (2-tailed) and values marked with ${ }^{\star * *}$ indicate regression analysis of relationship is significant $\leq 0.05$.

The mean scores obtained were used to rank the six constructs in the order of most prevalent personal intervening psychological risk factor identified among the research participants. The results indicate that the most prevalent factor was low self-esteem, followed by poor time management skills and poor relationship with others. Low self-esteem has been identified as a personal factor that could make a construction employee vulnerable to the triggers of psychological ill-being conditions of workaholism and burnout [1] [6]. A person with low self-esteem would likely be exposed to abusive and over demanding supervisors in the construction industry. Low self-esteem is, therefore, a personal factor that affects one's psychological well-being and general health [2]. To enhance construction employees' psychological health, there is the need for positive core self-esteem, as this is an individual's personal resource in the management of their occupational psychological health [14] [18].

Construction employees with poor time management skills would likely be exposed to tight deadline pressures, which could lead to the employees experiencing psychological ill-being condition such as stress or burnout. Harris et. al. [52] also confirmed that individuals with good time management skills mitigate all kinds of stressors at the workplace, enhancing the employees' psychological health and well-being. Poor relationship with people especially supervisors and co-workers could also arouse the circumstances that lead to psychological ill-being conditions of the construction employees [2] [3]. There is a need for construction employees to develop positive relations with others especially coworkers, as this could influence their psychological health, leading to satisfaction and fulfillment in life [6] [7]. Evidently, individuals who have high-quality relationship with people, including their immediate supervisors and colleagues and are seen to be more accepting, have high occupational psychological well-being symptoms such as work engagement and job satisfaction [11]. Positive relations with others could be expressed for instance by being genuinely concerned about the welfare of others [14]. Positive personal factors such as higher self-esteem, good time management skills and good relationship with others could help 
promote a psychologically safe and healthy construction industry.

The other personal intervening psychological risk factors specifically unproductive core beliefs, negative personality traits and poor self-concept evaluation on performance were also revealed to be significant among the research participants. A person's productive belief such as their life is meaningful and purposeful, give them a purpose to live for something in their lifetime [6] [32]. This can bring forth a sense of personal growth and continual development in that person, as he or she opens up to new experiences in life [14]. Unproductive core beliefs are personal factors that could expose construction employees to the triggers of psychological ill-being conditions such as perceived poor working conditions, resulting in conditions such as anxiety and depression [1] [2]. Earlier researchers provided evidence that individuals who have positive core self-beliefs usually buffer any adverse emotional and social effects emanated from external sources, thus enhancing the psychological well-being of the individual [32]]. There is the need for positive productive core beliefs to counteract the unproductive core beliefs the construction employees hold, and this will lead to psychological well-being and health [31].

Negative personality traits such as neuroticism, hostility, pessimism and lack of autonomy, are significant factors that could also expose the construction employees to the risk factors associated with psychological health conditions. Neuroticism depicts a person's sensitive to criticisms and evidence shows this personality trait is positively related to psychological ill-being indicators, affecting one's physical, emotional and mental health [6]. Earlier researchers revealed that persons with high levels of neuroticism are likely to experience psychological ill-being with signs of emotional exhaustion, anger, depression, anxiety, and vulnerabilities [29] [39]. Hostility as a personality trait has also been proved to be one of the most potent causes of cardiovascular diseases, which positively relates to other environmental risk factors [7]. There is a need for the development of positive personality trait such as friendliness, to help enhance and prevent critical psychological health conditions among the construction employees in Ghana [2]. People who are pessimistic also tend to focus on only the negative aspects of life, which predisposes them to psychological ill-being conditions such as distress and dissatisfaction of most aspects of life [7]. Pessimistic personality tends to worry a lot, and this can be seen in the responses presented by some of the construction workers interviewed. A study by Mäkikangas et al. [4] also established a relationship between occupational psychological well-being determinants such as job satisfaction and engagement with the positive personality traits of the individuals such as autonomy and resilience.

Persons who have poor self-concept evaluations are likely to have negative emotional reactions affecting their psychological well-being, general behaviors and attitudes to work [2]. Poor self-evaluation concept on one's job performance could expose them to the triggers of occupational psychological ill-being conditions of workaholism and burnout such as abusive and overdemanding supervisors, limited time for relaxation and poor working conditions [36] [37]. These 
could affect their occupational psychological well-being such as work engagement and job satisfaction [2]. Similarly, research by Zhang et al. [38] revealed that individuals with high positive self-concept evaluation of their mental functioning and creativity, were positively related with occupational psychological well-being indicators such as job satisfaction and work engagement. Poor selfconcept evaluation could, therefore, make the individual construction employee vulnerable to the experiences of psychological ill-being conditions, with symptoms manifested as frustration, anxiety, worry, depression, anger and the likes [36]. As a person's attitude, which is a psychological indicator is therefore likely to change when they perceive successful work performance and contribution to the productivity of the organization [6].

Previous studies advocated that demographic factors such as age, educational level, and marital status could predict a person's vulnerability to the risks of psychological disorders [40] [46] [49]. This study employed correlation analysis to determine the relationship between the six personal intervening factors and demographic factors. The results obtained from the correlation analysis are further checked by employing regression analysis as shown in $\mathrm{Ta}$ ble 4. The results indicate that demographic factors of age and marital status have no significant correlation with any of the six personal intervening psychological risk factors. These findings conform with studies conducted by previous researchers such as Cheng et al. [43] and Ahola et al. [44], who advocated that the age or marital status of a person has no significant relation with psychological risk factors such as one's personal factors. Negative personality and poor relationship with others as personal intervening factors also had no significant correlation with any of the demographic factors. The findings from this study, therefore, indicate that the age, marital status or educational level has no correlation and thus cannot predict personal intervening psychological risk factors of negative personality trait and poor relationship with others. This is also in conformity with studies conducted by Anderzen and Arnetz [23]. Educational level as a demographic factor, however, revealed a significant correlation with four of the six personal intervening factors, specifically self-esteem, time management skills, productive core beliefs and self-concept evaluation on performance.

Independent two-sample T-test was used to compare the means of the respondents based on their educational level with the four personal intervening factors that have significant relations. The respondents were grouped into two, namely a highly-educated group and a less-educated group. The highly educated group consisted of respondents with graduate educational level or above. The less educated group consisted of respondents with the following educational level; Ghana Certificate Exams "A" level, Ghana Certificate Exams "O" level, Junior High School level, Secondary School level and Technical or Vocational level. Table 5 presents the results of this comparison.

The results based on the group's mean score indicate that the highly educated construction employees had better self-esteem, time management skills, productive 
Table 5. Comparison of results between highly educated ${ }^{(\mathrm{a})}$ and less educated ${ }^{(\mathrm{b})}$ construc- $^{-}$ tion employees.

\begin{tabular}{llcccc}
\hline No. Personal Factors & Groups Mean & $\begin{array}{c}\text { Groups } \\
\text { Standard } \\
\text { deviation }\end{array}$ & & \multicolumn{2}{c}{$\begin{array}{c}\text { Levene's test for } \\
\text { equality of variance }\end{array}$} \\
\cline { 5 - 6 } & & F-value & P-value \\
\hline 1 & Low self-esteem & $3.61^{\mathrm{a}}, 4.31^{\mathrm{b}}$ & $1.597^{\mathrm{a}}, 1.213^{\mathrm{b}}$ & 26.870 & 0.000 \\
2 & Poor time management skills & $3.58^{\mathrm{a}}, 3.87^{\mathrm{b}}$ & $1.674^{\mathrm{a}}, 1.437^{\mathrm{b}}$ & 12.657 & 0.000 \\
3 & $\begin{array}{l}\text { Poor self-concept evaluation } \\
\text { on performance }\end{array}$ & $2.95^{\mathrm{a}}, 3.45^{\mathrm{b}}$ & $1.454^{\mathrm{a}}, 1.484^{\mathrm{b}}$ & 10.642 & 0.001 \\
4 & Unproductive core beliefs & $2.67^{\mathrm{a}}, 3.32^{\mathrm{b}}$ & $0.996^{\mathrm{a}}, 1.412^{\mathrm{b}}$ & 18.512 & 0.000 \\
\hline
\end{tabular}

Note: Values marked with (a) represent scores from the highly educated construction employees' group and values marked with (b) represent scores from the less educated construction employees' group.

core beliefs and self-concept evaluation on performance. This result is also in conformity with studies of Du et al. [46] and Rashkovits and Livne [47], which revealed that education could impact positively a person's thinking, behaviour and coping capabilities, with effects on a person's psychological health and well-being.

\section{Conclusions}

Personal-related factors could be very significant to the issues of occupational psychological health management in the construction industry. This study aims to explore the need for psychological health interventions in the construction industry by exploring personal factors that could make construction employees vulnerable to occupational psychological disorders. For this reason, this research focused on personal factors that could make construction employees vulnerable to the triggers of occupational psychological disorders such as abusive and overdemanding supervisors, tight deadline pressures, poor working conditions and limited time for relaxation. The personal-related psychological factors explored in this study included: low self-esteem, unproductive core beliefs, negative personality traits, poor time management skills, poor self-evaluation concepts on performance and poor relationship with others. Previous studies have revealed that these personal factors have a link with the core aspect of psychological resource theory.

A non-probability sampling technique, specifically purposive sampling method was adopted in selecting the research participants. The participants in the study were selected on the basis that they have some work experience in the construction industry and belong to either a construction profession or work trade. Low self-esteem, poor time management skills and poor relationship with others were most prevalent among the participants of this study. These personal-related factors could positively predict occupational psychological disorders such as burnout and workaholism among the construction employees. For instance, a construction employee with low self-esteem could be vulnerable to abusive and overdemanding supervisors, which could lead to the employee experiencing psychological disorders of workaholism. Also, a construction employee 
with poor time management skills could be faced with tight deadline pressures, which could lead to psychological disorders of job burnout. Construction employees who have a poor relationship with others could also cause violence at the construction workplace, which could result in hostility, aggression, discrimination and offensive behaviours among the employees. This research thus supports the assumption that perceptions of psychological disorders such as workaholism, job stress or burnout, are not just a product of work conditions, but personal factors.

This study further investigates the relationship between the six personal intervening factors and demographic factors specifically age, educational level and, marital status. Correlation and regression analyses are employed for this analysis. The results indicate that the age and marital status of the respondents have no significant relationship with any of the six personal intervening factors. However, the educational level of the respondents reveals a significant relationship with four of the personal factors, specifically self-esteem, time management skills, productive core beliefs and self-concept evaluation on performance. That is, the highly educated construction employees have lower means scores, which indicate they have higher self-esteem, better time management skills, higher productive core beliefs and better self-concept evaluation on performance than the less educated respondents. Education is, therefore, an important contributory factor to reduce the vulnerability of construction employees to the risks of psychological disorders.

There is a need for construction employees to take advantage of educational programs and adopt positive personal characteristics to enhance their psychological well-being. This study, therefore, recommends psychological health preventive strategies for the construction employee by focusing on positive personality factors such as high self-esteem, productive core beliefs, positive personality traits, good self-concept evaluation on performance and good time management skills. Though not all employees exposed to similar conditions develop the same psychological ill-being conditions, these personal factors would likely reduce construction employees' vulnerabilities to the risks of psychological disorders. These personal factors can also influence the construction employees' commitment and work engagement in their respective construction companies.

The study findings serve as a basis for further studies into occupational psychological health management and can be a form of reference for academicians, students, and future researchers. As findings of this research broaden perceptions on occupational psychology of construction employees, thereby offering deeper insights into issues that could enhance psychological health management in the construction industry. Further research would investigate the biggest challenge for the interventions to reduce the occupational psychological disorders in the construction industry.

\section{Acknowledgements}

This paper forms part of a research project from which other deliverables have 
been produced with different objectives but sharing common background, methodology and same research participants. This research work is fully supported by the Hong Kong Ph.D. fellowship scheme and the Hong Kong Polytechnic University.

\section{Data Availability Statement}

All data generated or analyzed during the study are included in this article. Data generated or analyzed during the study are also available from the corresponding author by request.

\section{Conflicts of Interest}

The authors declare no conflicts of interest regarding the publication of this paper.

\section{References}

[1] Landy, F.J. and Conte, J.M. (2016) Work in the 21st Century: An Introduction to Industrial and Organizational Psychology. 5th Edition, Wiley, American Psychological Association, Hoboken.

[2] O’Donoghue, A., Conway, E. and Bosak, J. (2016) Abusive Supervision, Employee Well-Being and Ill-Being: The Moderating Role of Core Self-Evaluations. Emotions and Organizational Governance. Research on Emotion in Organizations, 12, 3-34. https://doi.org/10.1108/S1746-979120160000012001

[3] Ashkanasy, N.M. and Daus, C.S. (2002) Emotions in the Workplace: The New Challenge for Managers. The Academy of Management Executive, 16, 76-86. https://doi.org/10.5465/ame.2002.6640191

[4] Mäkikangas, A., Rantanen, J., Bakker, A.B., Kinnunen, M.L., Pulkkinen, L. and Kokko, K. (2015) The Circumplex Model of Occupational Well-Being: Its Relation with Personality. Journal for Person-Oriented Research, 1, 115-129. https://doi.org/10.17505/jpor.2015.13

[5] Leung, M.Y., Chan, I.Y.S. and Olomolaiye, P. (2008) Impact of Stress on the Performance of Construction Project Managers. Journal of Construction Engineering and Management, 134, 644-652. https://doi.org/10.1061/(ASCE)0733-9364(2008)134:8(644)

[6] Quick, J.C., Wright, T.A., Adkins, J.A., Nelson, D.L. and Quick, J.D. (2013) Preventive Stress Management in Organizations. 2nd Edition, American Psychological Association, Washington DC. https://doi.org/10.1037/13942-000

[7] Rivkin, W., Diestel, S. and Schmidt, K.H. (2015) Psychological Detachment: A Moderator in the Relationship of Self-Control Demands and Job Strain. European Journal of Work and Organizational Psychology, 24, 376-388. https://doi.org/10.1080/1359432X.2014.924926

[8] Leung, M.Y. and Chan, I.Y.S. (2012) Exploring Stressors of Hong Kong Expatriate Construction Professionals in Mainland China: Focus Group Study. Journal of Construction Engineering and Management, 134, 644-652. https://doi.org/10.1061/(ASCE)0733-9364(2008)134:8(644)

[9] Greenberg, J.S. (2013) Comprehensive Stress Management. 13th Edition, Wm. C. Brown Publishers, Dubuque. 
[10] Afshar, H., Roohafza, H.R., Keshteli, A.H., Mazaheri, M., Feizi, A. and Adibi, P. (2015) The Association of Personality Traits and Coping Styles According to Stress Level. Journal of Research in Medical Sciences. The Official Journal of Isfahan University of Medical Sciences, 20, 353-358.

[11] Blaxton, J.M. and Bergeman, C.S. (2017) A Process-Oriented Perspective Examining the Relationships among Daily Coping, Stress, and Affect. Personality and Individual Differences, 104, 357-361. https://doi.org/10.1016/j.paid.2016.08.041

[12] Glenn, R.S. (2001) The Self-Esteem Workbook. $2^{\text {nd }}$ Edition, New Harbinger Publications, Inc., Oakland.

[13] Steinberg, H., Carius, D. and Fontenelle, L.F. (2017) Kraepelin's Views on Obsessive Neurosis: A Comparison with DSM-5 Criteria for Obsessive-Compulsive Disorder. Brazilian Journal of Psychiatry, 39, 355-364. https://doi.org/10.1590/1516-4446-2016-1959

[14] Horn, J.E.V., Taris, T.W., Schaufeli, W.B. and Schreus, P.J.G. (2004) The Structure of Occupational Wellbeing: A Study among Dutch Teachers. Journal of Occupational and Organizational Psychology, 77, 365-375. https://doi.org/10.1348/0963179041752718

[15] Plopa, M., Plopa, W. and Skuzińska, A. (2017) Bullying at Work, Personality and Subjective Well-Being. Journal of Occupational Health Psychology, 22, 19-27. https://doi.org/10.1037/a0040320

[16] Bono, J.E. and Judge, T.A. (2003) Core Self-Evaluations: A Review of the Trait and Its Role in Job Satisfaction and Job Performance. European Journal of Personality, 17, 5-18. https://doi.org/10.1002/per.481

[17] Martinko, M.J., Harvey, P., Brees, J.R. and Mackey, J. (2013) A Review of Abusive Supervision Research. Journal of Organizational Behavior, 34, 120-137. https://doi.org/10.1002/job.1888

[18] Tims, M., Bakker, A. and Xanthopoulou, D. (2011) Do Transformational Leaders Enhance Their Followers' Daily Work Engagement? The Leadership Quarterly, 22, 121-131. https://doi.org/10.1016/j.leaqua.2010.12.011

[19] French, J. (2005) Work Locus of Control as a Moderating Influence on the Quality of Work Life for Radiation Therapists. Canadian Journal of Medical Radiation Technology, 36, 12-16. https://doi.org/10.1016/S0820-5930(09)60052-9

[20] Schyns, B. and Day, D. (2010) Critique and Review of Leader Member Exchange Theory: Issues of Agreement, Consensus, and Excellence. European Journal of Work and Organizational Psychology, 19, 1-29. https://doi.org/10.1080/13594320903024922

[21] Masood, A. (2013) Effects of Job Stress on Employee Retention: A Study on Banking Sector of Pakistan. International Journal of Scientific and Research Publications, 3, 2250-3153.

[22] Sogaard, A.J., Dalgard, O.S., Holme, I., Roysamb, E. and Haheim, L.L. (2008) Associations between Type A Behavior Pattern and Psychological Distress. Social Psychiatry and Psychiatric Epidemiology, 43, 216-223. https://doi.org/10.1007/s00127-007-0288-7

[23] Anderzen, I. and Arnetz, B.B. (1997) Psychophysiological Reactions during the First Year of a Foreign Assignment: Results of a Controlled Longitudinal Study. Work and Stress. An International Journal of Work, Health and Organisations, 11, 304-318. https://doi.org/10.1080/02678379708252994

[24] Lee, L.Y. and Sukoco, B.M. (2008) The Mediating Effects of Expatriate Adjustment 
and Operational Capability on the Success of Expatriation. Social Behavior and Personality, 36, 1191-1204. https://doi.org/10.2224/sbp.2008.36.9.1191

[25] Shoji, K., Cieslak, R., Smoktunowicz, E., Rogala, A., Benight, C.C. and Luszczynska, A. (2016) Associations between Job Burnout and Self-Efficacy: A Meta-Analysis. Anxiety, Stress, and Coping, 29, 367-386. https://doi.org/10.1080/10615806.2015.1058369

[26] Vollrath, M. (2001) Personality and Stress. Scandinavian Journal of Psychology, 42, 335-347. https://doi.org/10.1111/1467-9450.00245

[27] Abbott, R.A., Croudace, T.J., Ploubidis, G.B., Kuh, D., Richards, M. and Huppert, F.A. (2008) The Relationship between Early Personality and Midlife Psychological Well-Being: Evidence from a UK Birth Cohort Study. Social Psychiatry and Psychiatric Epidemiology, 43, 679-687. https://doi.org/10.1007/s00127-008-0355-8

[28] Hobfoll, S.E. (2002) Social and Psychological Resources and Adaptation. Review of General Psychology, 6, 307-324. https://doi.org/10.1037/1089-2680.6.4.307

[29] Avey, J.B., Luthans, F., Smith, R.M. and Palmer, N.F. (2010) Impact of Positive Psychological Capital on Employee Wellbeing over Time. Journal of Occupational Health Psychology, 15, 17-28. https://doi.org/10.1037/a0016998

[30] Luthans, F., Avolio, B.J., Avey, J.B. and Norman, S.M. (2007) Positive Psychological Capital: Measurement and Relationship with Performance and Satisfaction. Journal of Personnel Psychology, 60, 541-572. https://doi.org/10.1111/j.1744-6570.2007.00083.x

[31] Xanthopoulou, D., Bakker, A.B. and Fischbach, A. (2013) Work Engagement among Followers Facing Emotional Demands: The Role of Personal Resources. Journal of Personnel Psychology, 12, 74-84. https://doi.org/10.1027/1866-5888/a000085

[32] Sheeran, P., Maki, A., Montanaro, E., Avishai-Yitshak, A., Bryan, A., Klein, W.M., Miles, E. and Rothman, A.J. (2016) The Impact of Changing Attitudes, Norms, and Self-Efficacy on Health-Related Intentions and Behavior: A Meta-Analysis. Health Psychology, 35, 1178-1188. https://doi.org/10.1037/hea0000387

[33] Judge, T.A., Scott, B.A. and Ilies, R. (2006) Hostility, Job Attitudes, and Workplace Deviance: Test of a Multilevel Model. Journal of Applied Psychology, 91, 126-138. https://doi.org/10.1037/0021-9010.91.1.126

[34] Weiss, H.M. and Rupp, D.E. (2011) Experiencing Work: An Essay on a Person-Centric Work Psychology. Industrial and Organizational Psychology. Perspectives on Science and Practice, 4, 83-97. https://doi.org/10.1111/j.1754-9434.2010.01302.x

[35] Van Beek, I., Hu, Q., Schaufeli, W.B., Taris, T.W. and Schreurs, B.H. (2012) For Fun, Love, or Money: What Drives Workaholic, Engaged, and Burned-Out Employees at Work? Applied Psychology, 61, 30-55. https://doi.org/10.1111/j.1464-0597.2011.00454.x

[36] Aryee, S., Walumbwa, F.O., Zhou, Q. and Hartnell, C.A. (2012) Transformational Leadership, Innovative Behavior, and Task Performance: Test of Mediation and Moderation Processes. Human Performance, 25, 1-25. https://doi.org/10.1080/08959285.2011.631648

[37] Spence, J.T. and Robbins, A.S. (1992) Workaholism: Definition, Measurement, and Preliminary Results. Journal of Personality Assessment, 58, 160-178. https://doi.org/10.1207/s15327752jpa5801_15

[38] Zhang, H., Kwan, H.K., Zhang, X. and Wu, L.Z. (2014) High Core Self-Evaluators 
Maintain Creativity: A Motivational Model of Abusive Supervision. Journal of Management, 40, 1151-1174. https://doi.org/10.1177/0149206312460681

[39] Yang, F., Li, X., Zhu, Y., Li, Y. and Wu, C. (2017) Job Burnout of Construction Project Managers in China: A Cross-Sectional Analysis. International Journal of Project Management, 35, 1272-1287. https://doi.org/10.1016/j.ijproman.2017.06.005

[40] Chaoping, L. and Kan, S. (2003) The Influence of Distributive Justice and Procedural Justice on Job Burnout. Acta Psychologica Sinica, 35, 677-684.

[41] Erickson, R. and Grove, W. (2007) Why Emotions Matter: Age, Agitation, and Burnout among Registered Nurses. The Online Journal of Issues in Nursing, 13, 1-13.

[42] Johnson, S.J., Holdsworth, L., Hoel, H. and Zapf, D. (2013) Customer Stressors in Service Organizations: The Impact of Age on Stress Management and Burnout. European Journal of Work and Organizational Psychology, 22, 318-330. https://doi.org/10.1080/1359432X.2013.772581

[43] Cheng, Y., Chen, I.S., Chen, C.J., Burr, H. and Hasselhorn, H.M. (2013) The Influence of Age on the Distribution of Self-Rated Health, Burnout and Their Associations with Psychosocial Work Conditions. The Journal of Psychosomatic Research, 74, 213-220. https://doi.org/10.1016/j.jpsychores.2012.12.017

[44] Ahola, K., Honkonen, T., Virtanen, M., Aromaa, A. and Lönnqvist, J. (2008) Burnout in Relation to Age in the Adult Working Population. Journal of Occupational Health, 50, 362-365. https://doi.org/10.1539/joh.M8002

[45] Brewer, E.W. and Shapard, L. (2004) Employee Burnout: A Meta-Analysis of the Relationship between Age or Years of Experience. Human Resource Development Review, 3, 102-123. https://doi.org/10.1177/1534484304263335

[46] Du, H., Qin, L., Jia, H., Wang, C., Zhan, J. and He, S. (2015) Relationship between Job Burnout and Cognitive Function and Influencing Factors of Job Burnout among Medical Staff. Chinese Journal of Industrial Hygiene and Occupational Diseases, 33, 676-678.

[47] Rashkovits, S. and Livne, Y. (2013) The Effect of Education Level on Psychological Empowerment and Burnout-The Mediating Role of Workplace Learning Behaviors. International Journal of Psychological and Behavioral Sciences, 7, 1896-1901.

[48] Mohammadpoorasl, A., Maleki, A. and Sahebihagh, M.H. (2012) Prevalence of Professional Burnout and Its Related Factors among Nurses in Tabriz in 2010. Iranian Journal of Nursing and Midwifery Research, 17, 524-529.

[49] Maslach, C., Schaufeli, W.B. and Leiter, M.P. (2001) Job Burnout. The Annual Review of Psychology, 52, 397-422. https://doi.org/10.1146/annurev.psych.52.1.397

[50] Leung, M.Y., Olomolaiye, P., Chong, A. and Lam, C.C.Y. (2005) Impacts of Stress on Estimation Performance in Hong Kong. Construction Management and Economics, 23, 891-903. https://doi.org/10.1080/0144619042000326701

[51] Enshassi, A., Al Swaity, E. and Arian, F. (2016) Investigating Common Causes of Burnout in the Construction Industry. International Journal of Construction Project Management, 8, 43-56.

[52] Harris, K., Harvey, P. and Kacmar, K. (2009) Do Social Stressors Impact Everyone Equally? An Examination of the Moderating Impact of Core Self-Evaluations. Journal of Business and Psychology, 24, 153-164.

https://doi.org/10.1007/s10869-009-9096-2. 